\title{
Accuracy of ultrasonography for the diagnosis of pneumoperitoneum
}

\author{
P Nazerian*, C Tozzetti, A Petrioli, M Ottaviani, F Trausi, M Baioni, S Grifoni \\ From 10th WINFOCUS World Congress on Ultrasound in Emergency and Critical Care \\ Kuala Lumpur, Malaysia. 16-19 November 2014
}

\section{Background}

Clinical signs and symptoms of pneumoperitoneum are not specific and abdomen radiography is positive in less than $50 \%$ of cases. Ultrasonography (US) accuracy for the diagnosis of pneuperitoneum is still unknown.

\section{Objective}

1) define the accuracy of abdominal US for the diagnosis of pneumoperitoneum; 2) define the accuracy of a "2 scan-fast exam" vs a full abdominal exam; 3) compare accuracy of US and abdomen radiography

\section{Patients and methods}

Study patients: 11 consecutive adults with a diagnosis of pneumoperitoneum by CT. Control patients: 11 consecutive adults with severe acute abdominal pain with a diagnosis other than pneumoperitoneum by CT. US examination has been performed with a convex and a linear probe using the following scans: epigastrium, right and left hypocondrium, umbelical area and right hypocondrium. All exams were recorded in a video of 5 seconds and each videos reviewed by 2 radiologists and 2 senior physicians blinded to other imaging studies. The reviewers fulfilled a standardized form signing for each scan either presence or absence of pneumoperitonem signs (enhancement of the peritoneum stripe with ring-down artifacts or "comet tails" starting from peritoneum). If one of the signs of pneumopeitoneum was present in at least one scan, the patient was considered to have a US diagnosis of pneumoperitoneum. The reviewers also evaluated abdomen radiography for the presence/absence of pneumoperitoneum. CT was considered the gold standard.

\footnotetext{
* Correspondence: pnazerian@hotmail.com

Department of Emergency Medicine and Radiology Department, Careggi University Hospital, Firenze, Italy
}

\section{SpringerOpen ${ }^{\circ}$}

(c) 2015 Nazerian et al; licensee Springer. This is an Open Access article distributed under the terms of the Creative Commons Attribution License (http://creativecommons.org/licenses/by/4.0), which permits unrestricted use, distribution, and reproduction in any medium, provided the original work is properly cited.

\section{Results}

1) Accuracy of abdomen US was $88.6 \%$. Sensitivities of convex and linear probes were similar ( $88.6 \%$ vs $84.1 \%)$, while specificity of convex was lower than linear probe (81.8\% vs 95.5\%). 2) Accuracy of a "2 scan-fast exam" was similar to global exam (87.5\%). 3) Abdominal radiography sensitivity (72.2\%) was lower than US while specificity (92.5\%) was higher.

Abdominal US has a good accuracy. The 2 scan-fast exam has a similar accuracy of the full abdominal exam. US sensitivity is superior to abdominal radiography thus ultrasonography can be a useful imaging modality for the detection of pneumoperitoneum.

Published: 9 March 2015

doi:10.1186/2036-7902-7-S1-A14

Cite this article as: Nazerian et al:: Accuracy of ultrasonography for the diagnosis of pneumoperitoneum. Critical Ultrasound Journal 2015

7(Suppl 1):A14.

Submit your manuscript to a SpringerOpen ${ }^{\bullet}$ journal and benefit from:

- Convenient online submission

Rigorous peer review

- Immediate publication on acceptance

- Open access: articles freely available online

- High visibility within the field

- Retaining the copyright to your article

Submit your next manuscript at $>$ springeropen.com

\section{Conclusions}

